Wilfrid Laurier University

Scholars Commons @ Laurier

Spring 1986

\title{
An Action-Oriented Assessment of the Housing and Social Support Needs of Long-Term Psychiatric Clients
}

\author{
Geoffrey Nelson \\ Wilfrid Laurier University, gnelson@wlu.ca \\ Mary Earls \\ Wilfrid Laurier University
}

Follow this and additional works at: https://scholars.wlu.ca/psyc_faculty

Part of the Psychiatry and Psychology Commons

\section{Recommended Citation}

Nelson, Geoffrey and Earls, Mary, "An Action-Oriented Assessment of the Housing and Social Support Needs of Long-Term Psychiatric Clients" (1986). Psychology Faculty Publications. 29.

https://scholars.wlu.ca/psyc_faculty/29

This Article is brought to you for free and open access by the Psychology at Scholars Commons @ Laurier. It has been accepted for inclusion in Psychology Faculty Publications by an authorized administrator of Scholars Commons@Laurier. For more information, please contact scholarscommons@wlu.ca. 


\title{
AN ACTION-ORIENTED ASSESSMENT OF THE HOUSING AND SOCIAL SUPPORT NEEDS OF LONG-TERM PSYCHIATRIC CLIENTS
}

\author{
GEOFFREY NELSON and MARY EARLS \\ Wilfrid Laurier University
}

\begin{abstract}
This paper describes the context and process, as well as the content, of an assessment of the housing and social support needs of long-term psychiatric clients in a community. The principles of the ecological perspective were used as a framework for conceptualizing and analyzing the data. Using key informant interviews, community forums, and a survey of the clients, it was found that a visible minority of the population has significant housing problems and lacks adequate aftercare and supervision. The ways in which the data have been utilized are described, along with directions for further action.
\end{abstract}

A frequent complaint about needs assessment and program evaluation studies is that the results are not often used (Weiss, 1972). To remedy this, Patton (1978) and others (Chavis, Stucky, \& Wandersman, 1983; Crocker \& George, 1985; Davis, 1982; Toro \& Keogh, 1984; Tyler, Pargament, \& Gatz, 1983; Walsh, 1985) have recommended and demonstrated the viability of an action-oriented approach in which the participants in the setting hosting the research collaborate with the researchers in the design, data collection and analysis, and utilization of the findings. In a sense, the field is beginning to rediscover Lewin's action research model (e.g., Ketterer, Price, \& Politser, 1980) which has been dormant for many years (Sanford, 1970).

A related concern is the narrowness of community research which tends to isolate a few variables for study and to report the findings regarding these variables in the traditional, objective, scientific report writing style. The problem with this approach is that it tends to ignore both the context in which the research occurs and the process of the research itself. For example, many outcome evalua-

\footnotetext{
We are indebted to Ken Parsons for his collaboration throughout this project and for his editorial comments on this paper. We would also like to acknowledge the assistance of Donna Cameron, Andrea Kamin, Amanda Kroger, and Joan McKay. An abbreviated version of this paper was presented at the Evaluation $\$ 85$ Conference, October 16-19. Toronto, Ontario, Correspondence should be directed to the first author who is with the Department of Psychology, Wilfrid Laurier University, Waterloo, Ontario N2L 3 C5.
} 
tions of social programs in Canada have shown few effects (Rutman, 1977). Arguing from a systems perspective, Etzioni (1969) has stated that such findings become understandable if one begins with the assumption that programs pursue many goals other than just clients' attainment of program goals (e.g., survival). The importance of this broad perspective is that careful attention to the context and process of community research can yield valuable qualitative data that can be useful in helping the researcher to understand the content of the research (i.e., the findings regarding the particular variables under study) (Campbell, 1974). Thus, the action-oriented approach to community research may be valuable not only in terms of practical utility, but also in terms of enhancing the process of scientific inquiry.

The purpose of this paper is to describe not only the content but also the context and process of an action-oriented assessment of the housing and social support needs of long-term psychiatric clients. The principles of the ecological perspective for community research, as outlined by Trickett, Kelly, and Vincent (1985), are used as a framework to examine and interpret the findings of the needs assessment, both at the level of the human service system and at the level of the individual. The utility of this approach for both understanding and action is the major focus of this article.

The ecological principle of interdependence focuses on the dynamic interaction of persons and their environments. At the level of the human service system, this principle suggests that attention must be paid to the links (or lack thereof) in the network of services for long-term psychiatric clients. Recent articles have found that community services for this population in Canada tend to be fragmented and inadequate (e.g.. Gerstein, 1984; Heseltine, 1983; Trainor \& Church, 1984). At the level of the individual client, the principle of interdependence points to the importance of examining the post-hospital social environments of long-term psychiatric clients to understand their psychological well-being.

The principle of adaptation asserts that coping and adaptation are the dominant means of change and growth. At the level of the human service system, one must consider how local communities cope and adapt to the influx of long-term psychiatric clients who are discharged from provincial mental hospitals. At the level of the individual client, housing and social support are important for clients' adaptation. The type of accommodation (Kruzich, 1985; McCarthy, Byrne, Harrison, \& Keithley, 1985; Sinnett \& Sachson, 1970) and the architectural quality and/or physical comfort of the accommodation (Moos \& Lemke, 1980) may be very important for the psychological well-being of long-term psychiatric clients. Similarly, the number of people in one's social network who provide different types of support (Cohen \& Sokolovsky, 1978; Pattison, Defrancisco, Wood, Frazier, \& Crowder, 1975; Sokolosvky, Cohen, Berger, \& Geiger, 1978) and the perceived quality of the support provided by members of one's social network (Turner, 1981; Turner, Frankel, \& Levin, 1983) have been shown to be important to the psychological well-being of long-term psychiatric clients. Following Herzberg. Mathapo, Wiener, and Wiesen's (1974) two-factor theory of human needs, we reasoned that quality of housing would be important for pain-avoidance needs (i.e., safety, security, etc.), while social support might be more important for 
growth needs (i.e., belonging, etc.). A more detailed presentation of the theory, derived predictions, and findings regarding this part of the study can be found in a companion paper (Earls \& Nelson, 1986).

The principles of cycling of resources focuses on the identification and development of resources. In this study, we were concerned not only with identifying the needs of long-term psychiatric clients with respect to housing and social support, but we also wanted to identify untapped resources and to create new resources to meet these needs. In other words, this priniciple suggests that for a needs assessment to be action-oriented it must be both a needs and resources assessment. Thus, in the process of data collection, we looked for various resources, including financial and human resources.

The principle of succession involves a longitudinal time perspective. It is well known that the problems experienced by long-term psychiatric clients in the community have not arisen overnight. Rather, there has been a shift in Canadian governmental policies from institutional care to the present era of deinstitutionalization (Barnes \& Toews, 1983). To change the present situation in Canadian communities, it is clear that a needs assessment is but a beginning point in the action research cycle. At the level of the individual client, it is important to recognize that clients' needs may change over time.

\section{METHOD}

\section{Beginnings of the Study}

This study was initiated by a retired school teacher who has been active in several organizations in the Region of Waterloo, Ontario to try to improve community services for long-term psychiatric clients. He is an informal leader of a group of parents who have grown children with long-term psychiatric problems. This person approached the authors in January of 1984 to do a study of the housing needs of long-term psychiatric clients, because it had been suggested to him by local mental health officials that the needs of this population in the region had to be documented before action could be taken.

Through meetings with this person, it was decided that the study would focus on people between the ages of 18 and 65 who had been hospitalized at least twice for psychiatric problems and who had been diagnosed as schizophrenic, chronic depressive, or manic-depressive. It was further decided that the goals of the study would be: (a) to determine the present housing conditions and needs of long-term psychiatric clients in Waterloo Region, (b) to determine untapped housing resources potentially available to these clients, and (c) to facilitate applying and lobbying for further needed housing from outside resources.

\section{Participants}

There were two main groups of participants. The first group consisted of key informants, including 24 agencies who refer long-term psychiatric clients for housing (e.g., hospitals, mental health, social service, and housing agencies, etc.); seven police and community legal service representatives; and 14 people who provide housing for long-term psychiatric clients. 
The second group consisted of 89 long-term psychiatric clients. The clients were predominantly men $(60 \%)$ with a mean age of 38 years (range $=18$ to 66 years). Almost $98 \%$ of the clients were not married. There was considerable variability in the educational level of the clients with more than half having a high school diploma or higher level of education. Few of the clients were employed and most received some type of government assistance. At least two-thirds of the sample had a monthly income of less than $\$ 500$, which is well below the poverty line. The clients lived in many different types of housing: rooming situation $(19.1 \%)$, private apartment $(24.7 \%)$, own home $(9.0 \%)$, parents' home $(20.2 \%)$, group home $(13.5 \%)$, and other $(13.5 \%)$.

\section{Needs Assessment Approaches and Procedure}

Several writers have described three general approaches to needs assessment: (a) indicator approaches (e.g., social indicators, rates under treatment), (b) community group approaches (e.g., key informant interviews, community forums), and (c) the survey approach (Bell, Nguyen, Warheit, \& Buhl, 1978; Milord, 1976; Siegel, Attkisson, \& Carson, 1978). These writers have argued for the use of more than one needs assessment approach in a given study for the purpose of "triangulation" of findings from different sources. It was decided not to use an indicator approach since a study of this type had already been conducted. In October, 1981, the Chief of Psychiatric Services at the Kitchener-Waterloo Hospital conducted a one-day point prevalence study by asking the major mental health agencies serving the region how many "long-term psychiatric clients" (using the same definition that was employed in this study) at each agency were in need of supervised housing. The results of this study indicated that at least 159 clients were in need of such housing.

The researchers decided on three needs assessment techniques: key informant interviews, community forums, and a client survey.

Phase I. Key informant interviews were used in this phase to obtain the perspective of human service workers and to help develop links and a coordinated effort between the various human service programs and personnel. The interviews were either conducted in person at the agency or by telephone. This phase concluded in June, 1984, with a community forum in which the findings from the key informant interviews were reviewed and feedback was solicited on a draft of an interview schedule to be used in the client survey. A total of 21 people representing various human service programs attended the forum.

Phase II. A survey of clients' perceptions of their needs for housing and social support was then conducted. During this phase, several agencies and purveyors of housing who were involved in the first phase of the study gave long-term psychiatric clients a letter from the researchers requesting their participation in the study. If the clients were interested in being interviewed, they were introduced to one of the interviewers. The purpose of the study and the rights of the clients in the research were reiterated by the interviewers, and those who consented participated in a structured interview. The interviews lasted about one-half hour to one hour in length. For various reasons, it was not possible to determine the proportion of consenters to refusers. The client interviews were completed by the end of December, 1984. This second phase of the study concluded with another community forum in April, 1985, which was attended by approximately 75 people (human service providers, clients, parents, politicians, etc.). The purpose of the forum was to review the findings from the second phase of the study and to plan for future action. The researchers presented the findings from the client survey and several key people from the community presented their perspectives on the issues. 


\section{Instruments}

Key informant interview schedules. Separate interview schedules were constructed for each of the following groups: (a) mental health, social service, and housing agencies, (b) police and community legal service workers, and (c) purveyors of housing. While the interview schedules for the three groups differed somewhat, all included items dealing with the perceptions as to whether or not housing is a problem for long-term psychiatric clients, the relative number of clients for whom housing is a problem, and the types of housing which are needed.

Client interview schedule. In addition to questions regarding demographic information and the type of housing in which the clients lived, the following two measures were included in the client interview schedule:

1. Housing Concerns - A measure of clients' perceptions of the physical and psychological comfort and architectural quality of their housing was adapted from the Rating Scale of Lemke and Moos' (1984) Multiphasic Environmental Assessment Procedure (MEAP). The following eight items from this scale were used: noise level, odor, quality of lighting, condition of walls and floors, cleanliness, condition of furniture, adequate number of windows, and interesting view from windows. At the first forum, nine other items were proposed by the key informants and subsequently added to the scale: do appliances work; are pets allowed; is there enough heat in the winter; is there enough hot water; does the plumbing work; are repairs done when needed; do you feel safe and secure in the building; would you recommend the place to a friend; and would you like this place as a home. All 17 items were answered on a "Yes" or "No" basis. Clients were also asked if they had access to kitchen, laundry room, bathroom, and recreational room, and if they had their own bedroom and enough space and privacy.

2. Social Support - Barrera's (1981) Arizona Social Support Interview Schedule (ASSIS) was used to assess clients' social support. Five areas of social support were assessed: guidance (advice), positive feedback (approval), physical assistance (tangible aid), social participation (recreation), and material aid (monetary aid). For each of these areas, respondents were asked how many people they could rely on to provide that type of support, and they were asked to rate their satisfaction with the support they received on three-point scales (e.g., "During the past month, would you have liked: a lot more advice, a little more advice, or was it about right?"').

\section{RESULTS}

\section{Phase I}

Content. There was strong agreement among the different groups of key informants that housing was a problem for long-term psychiatric clients. With regard to mental health, social service and housing agencies, $91 \%$ of the 24 respondents felt that housing was a problem for long-term psychiatric clients, and $77 \%$ felt that housing was a problem for at least half of their clients. Respondents felt that a range of housing services (group homes, cooperative apartments, etc.) was needed. 
The seven people from Waterloo Regional Police, Ontario Legal Aid Plan, and Waterloo Region Community Legal Services usually had contact with longterm psychiatric clients in the context of criminal allegations. They too felt that housing was a major problem for this population, and a range of housing services was needed.

Room and board was the most available type of housing in the area. A majority $(79 \%)$ of the housing services had some restrictions on the gender, age, and/or personal characteristics of clients accepted. Almost half $(43 \%)$ of the housing services had a waiting list, and $78 \%$ had turned away long-term psychiatric clients due to a shortage of bed space. Common problems experienced with long-term psychiatric clients included: the client not fitting into the program, insufficient social support in the community for clients and purveyors, insufficient financial support for clients and purveyors, etc. Once again, a range of housing alternatives was felt to be needed, with particular emphasis on the need for supervision and aftercare.

Context and process. The principles of the ecological perspective can be used to elucidate the context and process of the research at the level of the human service system. With regard to the principle of interdependence, local services tended to be sparse and fragmented. One agency operated two supervised group homes for long-term psychiatric clients (serving a total of about 20 clients) and there was an aftercare team of two people (also serving about 20 clients). These programs could hardly be considered adequate for a region with a population of more than 300,000 . In terms of the principle of adaptation, local services were overtaxed. No local agency had a mandate or assumed major responsibility for services for long-term psychiatric clients. Service providers were also frustrated by the region's low vacancy rate (less than .3\%), making it very difficult to refer clients for suitable and affordable housing.

In spite of these difficulties, the principle of cycling of resources brought our attention to many resources. The initiator of the study had increased public awareness of the issues through his various efforts. The university became a resource through our involvement. Other individuals and agencies who were interiewed indicated their willingness to be involved and to help. Finally, a Summer Canada Works grant was obtained to fund two people for the second phase of the study. Consistent with the principle of succession, we found that this first phase of the project had initiated some local momentum to deal with the issues.

Finally, the research relationship was a very important part of the process during this phase of the research. Human service providers told us many tales of woe regarding their prior involvement in other research projects. The most frequently cited complaints were that nothing useful had ever come out of other research projects in which they had been involved and that they had rarely received any feedback on the findings of these projects. In this study, we sent letters of feedback summarizing each aspect of the research and the minutes of the community forum to all who participated. Key informants also gave useful feedback to us at the community forum regarding the client survey. It was also the key informants who stressed the importance of aftercare and supervised living situations (i.e., social support) to expand our original focus which was solely on. housing. 


\section{Phase II}

Content. With regard to housing, there was a visible minority of the 89 clients who did not have their own room $(18.0 \%)$ and who felt that they did not have enough privacy $(28.1 \%)$ or space $(24.7 \%)$. Moreover, some of the clients did not have access to a recreational room $(41.6 \%)$, laundry room $(27.0 \%)$, and kitchen $(12.4 \%)$. Of the 17 housing concerns, the percentage of clients reporting different numbers of concerns were as follows: no concerns $(10.1 \%)$, one or two concerns $(41.5 \%)$, three or four concerns $(24.7 \%)$, five or six concerns $(8.9 \%)$, and seven or more concerns $(14.8 \%)$.

Turning to clients' perceptions of social support, the results of this aspect of the survey are presented in Table 1. Concerning network size, clients felt they could count on about four to five people, on the average, to provide most of the types of support. With regard to support satisfaction, the majority of clients tended to be satisfied with the support they had received in the areas of guidance, physical assistance, and tangible aid, but they were less satisfied with the support they had received in the areas of positive feedback and social participation.

TABLE 1

Client Responses to the Social Support Questions

Support Variable

\begin{tabular}{|c|c|c|c|c|c|}
\hline - & Guidance & $\begin{array}{l}\text { Positive } \\
\text { Feedback }\end{array}$ & $\begin{array}{l}\text { Physical } \\
\text { Assistance }\end{array}$ & $\begin{array}{c}\text { Social } \\
\text { Participation }\end{array}$ & $\begin{array}{c}\text { Tangible } \\
\text { Aid }\end{array}$ \\
\hline Network Size & 5.7 & 5.2 & 4.5 & 7.2 & 4.5 \\
\hline \multicolumn{6}{|l|}{ Support } \\
\hline \multicolumn{6}{|l|}{ Satisfaction } \\
\hline About right & $69.7 \%$ & $47.2 \%$ & $65.2 \%$ & $41.6 \%$ & $70.8 \%$ \\
\hline Little more needed & $15.7 \%$ & $21.3 \%$ & $22.5 \%$ & $25.8 \%$ & $7.9 \%$ \\
\hline Lot more needed & $10.1 \%$ & $31.5 \%$ & $10.1 \%$ & $28.1 \%$ & $14.6 \%$ \\
\hline No answer & $4.5 \%$ & $0.0 \%$ & $2.2 \%$ & $4.5 \%$ & $6.7 \%$ \\
\hline
\end{tabular}

Since only one group of people was studied, it is difficult to determine the relative importance of clients' perceptions of their needs for housing and social support. To help overcome this problem, we subdivided the sample into those clients who lived in a private apartment or boarding situation and those clients who lived in their own home, their parents' home, or one of the two supervised group homes. We compared these two groups' perceptions of their needs for housing and social support. The results of this analysis are presented in Table 2. Those clients who lived in their own home, in their parents' home, or in a supervised group home reported half as many housing concerns as those clients who lived in a private home or boarding situation, and twice the number of people within the residence who could be counted on to provide social support (the average number of people within the residence who could provide guidance, positive feedback, physical assistance, and social participation) and material support (tangible aid). The two groups did not differ significantly on the other measures of social support: total network size, support satisfaction, and frequency of support. 


\section{TABLE 2}

Mean Scores of Clients on Housing Concerns, Social Support and Material Support within Their Residences by Type of Residence

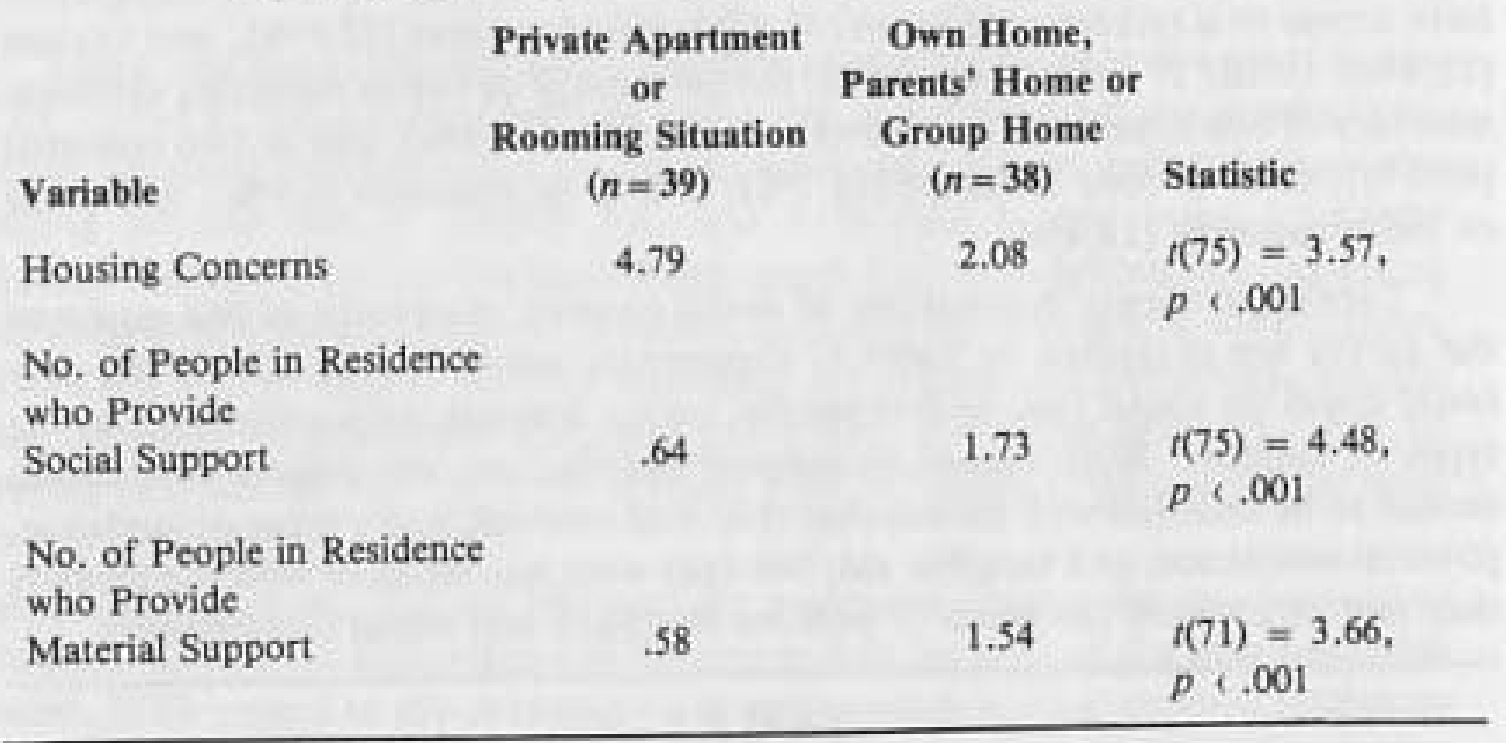

Context and process. At the level of the individual client, the principles of interdependence and adaptation suggest that housing conditions and social support are important to clients' post-hospital adaptation in the community. Both of these variables were found to be related to clients' self-reported psychological well-being (Earls \& Nelson, 1986). In the worst of cases, clients lived in run-down room-and-board homes or apartments in which they were isolated, lonely, and often poorly fed.

With regard to the cycling of resources, one of the original goals of the project was assumed by another agency during this phase of the study. The Canadian Mental Health Association/Waterloo Region employed a student on a summer grant to examine the area of untapped housing resources in the region. The results of her research led to a proposal for a housing registry which was accepted and implemented on a part-time basis by Waterloo Regional Homes for Mental Health (which has subsequently sought full-time funding for this program).

Trickett et al. (1985) have noted that events, as well as persons and settings, can be resources in community research. We fortuitously decided to hold our second community forum in April, less than one month before the May 2, 1985 , provincial election, and took the opportunity to invite all of the local candidates running for office, as well as the media. Several human service providers, clients, and parents of clients made moving statements during this meeting which significantly complemented our survey data. All these presentations were heard by the six political candidates (out of a possible 12) who attended the meeting. Several of these politicians (including one who was elected and subsequently appointed to a key cabinet position) and many human service agencies and individuals pledged to form a mental health coalition to plan further action on the issues. The Canadian Mental Health Association/Waterloo Region and Waterloo Regional Homes for Mental Health agreed to co-sponsor the coalition. Other events which occurred were several newspaper articles on the results of the study 
and the community forum which helped to increase public awareness of the issues.

The principle of succession suggests the need for a longitudinal time perspective. This first phase of the research helped to identify the problem, to increase public awareness of the issues, and to develop momentum for action. The next phase of the project will involve the development of a coalition to lobby government for more resources for housing and social support in the community for long-term psychiatric clients.

Through the research relationship with the settings and clients during this phase of the research, we encountered more tales of woe. At one setting, we could not understand why none of the clients were interested in being interviewed. We later found out that these clients had previously been subjected, without their informed consent, to a research project in which they were taken out to lunch so that the researchers could record their observations of the clients' social behaviour and table etiquette. Needless to say, these clients were humiliated by this experience and had learned to be "gun shy" of researchers. All clients who participated in the study received feedback on the findings if they wanted it.

The human service providers at the community forum also helped us to interpret the data. There appeared to be considerable agreement with the view expressed by one hospital-based pychologist that our client survey had underestimated the extent of the problem. Some thought that we had missed clients who have little or no contact with the formal human service system through which we worked. It was argued that these clients had the greatest needs and that our survey sampled proportionately more of the high functioning clients in the region.

Trickett et al. (1985) have also pointed out that an important part of the research relationship is the need to watch for unintended side effects. One important unintended side effect concerned the press. While the local newspaper generally reported the issues well, on more than one occasion it tended to describe psychiatric clients in a negative light (e.g., as poor housekeepers or as violent). We were concerned that such reporting might do more harm than good, raising the fears of community members who might already be reluctant to have such people live on their block, or of landlords who might become less likely to rent to long-term psychiatric clients.

\section{DISCUSSION}

It is clear from this study that long-term psychiatric clients and the people who serve them agree that housing and social support are significant problems for this segment of the community. A figure of about $15 \%$ of the clients reported seven or more concerns about their housing. If one accepts Heseltine's (1983) estimates that between $.35 \%$ and $1.0 \%$ of the population in Ontario require ongoing help for long-term psychiatric problems, then there are probably between 1,000 and 3,000 such clients in Waterloo Region, which has a population of slightly over 300,000 . If it is true that about $15 \%$ of the long-term psychiatric population has significant housing problems, then there are between 150 and 450 clients with such problems in the region. This estimate is similar to that found in 
the previously cited study that at least 159 long-term psychiatric clients require supportive housing in Waterloo Region.

With regard to social support, the estimates of network size for the various types of social support were fairly small (about five people) which is consistent with the findings of previous research (Cohen \& Sokolovsky, 1978; Pattison et al., 1975; Sokolovsky et al., 1978). Depending upon the type of support, $10 \%$ to $30 \%$ of the clients reported needing "a lot more support." Human service workers and the family and friends of long-term psychiatric clients should note that clients felt the need for more approval and social-recreation, not advice or more direct types of aid (tangible aid and physical assistance). The figures obtained in this study suggest that for both social support and housing, the problems and needs of this client group far outstrip currently available community resources. Moreover, since the sample was not drawn at random, we may have missed many clients who are functioning very poorly in the community. Thus, the figures obtained in this study are likely an underestimate, or at the least a very conservative estimate, of the extent of the problem.

Housing concerns and social support within one's residence were found to be related to the type of accommodation in which the clients were living. Clients who were living in their own home, a group home, or their parents' home reported fewer housing concerns and more people within their residence who could provide support than those who were living in a private apartment or rooming situation. However, very few clients are financially capable of having their own home or being lucky enough to be accepted into one of the few spaces available in the two supervised group homes. A total of $20 \%$ of the sample were living with their parents and they tended to be satisfied with their housing and social support within their residence. However, research has found that caring for a person with psychiatric problems can be very taxing on a family, both financially and emotionally (Potasznik \& Nelson, 1984). Thus, to the detriment of their own health, families are absorbing many of the problems created by a lack of community services, with parents facing the unenviable situation of providing " 24 hour' a day nursing care" at home to their grown up children because they are "not prepared to throw (their) children to the wolves" and "let them sleep under bridges or in gutters or in back alleys," as one parent forcefully stated at the second community forum. Moreover, in line with the principle of succession, parents are worried about the care their children will receive after the parents die.

Aside from the specific findings of this needs assessment, the ecological perspective was used to examine the involvement of all relevant stakeholders in the design of the research and in the attainment of the action goals of the project. The first goal of the project, to determine the housing and social support needs of long-term psychiatric clients in the region, has been reached. The second goal, to examine untapped sources of housing, was assumed by a local agency and expanded into the development of a housing registry program. The final goal was to apply and lobby for funds for additional services. To meet this goal, a coalition of the various stakeholders in the community has been formed. Thus, the approach that we took is a successful illustration of how community research can be improved, both in terms of the utility and the quality of the data, through collaboration with community members. 


\section{RÉSUMÉ}

Le présent article décrit le contexte, le processus et le contenu d'une analyse de besoins portant sur le logement et le support social nécessaires aux patients psychiatriques dans une communauté. Les principes d'une approche écologique ont été utilisés pour encadrer la conceptualisation et l'analyse des données. En se servant d'informateurs clés, de forums communautaires et d'un sondage auprès des patients, on a trouvé qu'une minorité visible rencontre de sérieux problèmes de logement et manque de soins à domicile et de support. La façon de décrire les données utilisées indiquent les directions à prendre dans les actions à poser.

\section{REFERENCES}

Barnes, G.E., \& Toews, J. (1983). Deinstitutionalization of chronic mental patients in the Canadian context, Canadian Psychology, 24, 22-36.

Barrerra, M. (1981). Social support in the adjustment of pregnant adolescents: Assessment issues. In B.H. Gottlieb (Ed.), Social network and social support (pp. 69-96). Beverly Hills: Sage.

Bell, R.A., Nguyen, T.D., Warheit, G.J., \& Buhl, J.M. (1978). Service utilization, social indicator, and citizen survey approaches to human service needs assessment. In C.C. Attkisson, W.A. Hargreaves, M.J. Horowitz, \& J.E. Sorenson (Eds.), Evaluation of human service programs (pp. 253-300). New York: Academic Press.

Campbell, D.T. (1974, September). Qualitative knowing in action research. Kurt Lewin Award Address, Society for the Psychological Study of Social Issues, presented at the annual meeting of the American Psychological Association.

Chavis, D.M., Stucky, P.E., \& Wandersman, A. (1983). Returning basic research to the community: A relationship between scientist and citizen. American Psychologist, 38, 424-434.

Cohen, C.I., \& Sokolosvky, J. (1978). Schizophrenia and social networks: Expatients in the inner city. Schzophrenia Bulletin, 4, 546-560.

Crocker, P.J., \& George, M.S. (1985). Participation and utilization: Assessing the skills training needs of the chronically mentally ill. Canadian Journal of Community Mental Health, 4, 73-82.

Davis, D.D. (1982). Participation in community intervention design. American Journal of Community Psychology, 10, 429-446.

Earls, M., \& Nelson, G. (1986). The relationship between long-term psychiatric clients' psychological well-being and their perceptions of housing ànd social support. Article in preparation.

Etzioni, A. (1969). Two approaches to organizational analysis: A critique and suggestion. In H.C. Schulberg, A. Sheldon, \& F. Baker (Eds.), Program evaluation in the heaith fields (Vol. I, pp. 101-120). New York: Behavioral Publications.

Gerstein, R. (1984). The final report of the'Mayor's Action Task Force on Discharged Psychiatric Patients. Toronto: City of Toronto.

Herzberg, F., Mathapo, J., Wiener, Y., \& Wiesen, L.E. (1974). Motivation-hygiene correlates of mental health: An examination of motivation inversion in a clinical population. Journal of Consulting \& Clinical Psychology, 42, 411-419.

Heseltine, G.F. (1983). Towards a blueprint for change: $A$ mental health policy and program perspective. London, Ontario: University of Western Ontario, Department of Psychiatry.

Ketterer, R.F., Price, R.H. \& Polister, P.E. (1980). The action research paradigm. In R.H. Price \& P.E. Polister (Eds.), Evaluation and action in the social environment (pp. 1-15). New York: Academic Press. 
Kruzich, J.M. (1985). Community integration of the mentally ill in residential facilities. American Journal of Community Psychology, 13, 553-564.

Lemke, S., \& Moos, R.H. (1984). Multiphasic environmental assessment procedure (MEAP): Data collection forms, Palo Alto, California: Social Ecology Laboratory and Stanford University Medical School.

MeCarthy, P., Byrne, D., Harrison, S., \& Keithley, J. (1985). Housing type, housing location, and mental health. Social Psychiatry, 20, 125-130.

Milord, J.T. (1976). Human service needs assessment: Three non-epidemiological approaches. Canadian Psychologist, 17, 260-269.

Moos, R.H., \& Lemke, S. (1980). Assessing the physical and architectural features of sheltered care settings, Journal of Gerontology, 35, 571-583.

Pattison, E., Defrancisco, D., Wood, P., Frazier, H., \& Crowder, J. (1975). A psychosocial kinship model for family therapy. American Journal of Psychiatry, 132, 1246-1250.

Patton, M.Q. (1978). Utilization-focused evaluation. Beverly Hills: Sage,

Potasznik, H., \& Nelson, G. (1984). Stress and social support: The burden experienced by the family of a mentally ill person. American Journal of Community Psychology, 12, 589-607.

Rutman, L. (1977). Social programme evaluations in Canada: An inventory. Ottawa, Ontario: Evaluation Research Training Institute, Centre for Social Welfare Studies, Carleton University.

Sanford, N. (1970). Whatever happened to action research? Journal of Social Issues, 26, 3-23.

Siegel, L.M., Attkisson, C.C., \& Carson, L.G. (1978). Need identification and program planning in the community context. In C.C. Attkisson, W.A. Hargreaves, M.J. Horowitz, \& J.E. Sorenson (Eds.), Evaluation of human service programs (pp. 215-252). New York: Academic Press.

Sinnett, E.R., \& Sachson, A.D. (Eds.). (1970). Transitional facilities in the rehabilitation of the emotionally disturbed. Lawrence, Kansas: University of Kansas Press.

Sokolovsky, J., Cohen, C., Berger, D., \& Geiger, J. (1978). Personal networks of exmental patients in a Manhattan SRO hotel. Human Organization, 37, 5-15.

Toro, P.A., \& Keogh, C.B. (1984, August). Collaborative research with a mutual help organization. Paper presented at the annual meeting of the American Psychological Association, Toronto.

Trainor, J., \& Church, K. (1984). A framework for support for people with severe mental disabilities. Toronto: Canadian Mental Health Association.

Trickett, E.J., Kelly, J.G., \& Vincent, T.A. (1985). The spirit of ecological inquiry in community research. In E. Susskind \& D.C. Klein (Eds.), Community research: Methods, paradigms, and applications (pp. 283-333). New York: Praeger.

Turner, R.J. (1981). Social support as a contingency in psychological well-being. Journal of Health \& Social Behavior, 22, 357-367.

Turner, R.J., Frankel, B.G., \& Levin, D. (1983). Social support: Conceptualization, measurement, and implications for mental health. In J.R. Greenley (Ed.), Research in community and mental health (Vol. III, pp. 67-111). Greenwich: JAI Press.

Tyler, F.B., Pargament, K.1., \& Gatz, M. (1983). The resource collaborator role: A model for interactions involving psychologists. American Psychologist, 38, 388-398.

Walsh, R.T. (1985, May). A social history of the research relationship in community psychology: Feedback report. Unpublished paper.

Weiss, C.H. (1972). Evaluation research: Methods of assessing program effectiveness. Englewood Cliffs, New Jersey: Prentice Hall. 